\title{
Subcutaneous Sterile Water Injection for Labor Pain: A Randomized Controlled Trial
}

\author{
Rai R, ${ }^{1}$ Uprety DK, ${ }^{1}$ Pradhan $T,{ }^{1}$ Bhattarai BK, ${ }^{2}$ Acharya $S^{3}$ \\ ${ }^{1}$ Department of Obsterics and Gynaecology, ${ }^{2}$ Department of Anesthesiology and Critical care, BP \\ Koirala Institute of Health Sciences, Dharan, \\ ${ }^{3}$ Department of Obstetrics and Gynaecology, College of Medical Sciences, Bharatpur, Nepal.
}

Aims: This study was done to evaluate the effectiveness of subcutaneous injection of sterile water compared with placebo in reduction of labor pain.

Methods: Two hundred and forty pregnant women at term planned for normal vaginal delivery during the first stage of labor were randomized to receive either subcutaneous injection of sterile water (study group, $\mathrm{n}=120$ ) or normal saline as placebo (control group, $\mathrm{n}=120$ ) at painful point in lumbosacral region. Pain score was measured before and 10, 45 and 90 minutes after the injections. Main outcome measured was reduction of low back labor pain using visual analogue scale.

Results: The mean pain score was equal in both groups prior to the injection. The pain scores were significantly lower among the intervention group compared to the control group at 10, 45, 90 minutes after injection. There was no difference between the two groups with regard to rate of instrumental delivery, cesarean rate and neonatal outcome.

Conclusions: The subcutaneous injection of sterile water administered at painful point in lumbosacral area was effective in reducing low back labor pain during labor.

Keywords: labor pain, low back pain, subcutaneous sterile water, visual analogue scale.

\section{INTRODUCTION}

Labor pain is one of the most painful events with severity ranging from women to women with $30 \%$ of them experiencing severe low back pain during labor. ${ }^{1}$ There is anatomical support for assumption that low back pain in labor is referred pain from the uterine cervix and corpus supplied by afferent neurons ending in dorsal horns of spinal segments $\mathrm{T} 10-\mathrm{L}^{1}$. Based on gate-control theory ${ }^{2}$ various techniques entailing anesthesia or stimulation of lumbosacral areas have been attempted in order to inhibit pain transmission to dorsal horn with varying results.

Although there are various methods for reducing labor pain, options are limited due to lack of monitoring facilities and human resource constraints especially in developing countries with resource poor set-up.

\section{CORRESPONDENCE}

Dr Rubina Rai

Department of Obstetrics and Gynaecology, BP Koirala Institute of Health Sciences, Nepal.

Email: rairubina@yahoo.com

Phone: +977-025525555-5345
In such condition sterile water injection seems to be a plausible option for this purpose. The aim of the present study was to evaluate the effectiveness of subcutaneous injection of sterile water compared to placebo for reduction of labor pain.

\section{METHODS}

The study included 240 pregnant women at more than 37 weeks of gestation who were admitted in labor room of BP Koirala institute of health sciences. A randomized single blind trial was conducted. To qualify for participation in study they had to be in active phase of first stage of labor with cervical dilatation of more than $4 \mathrm{~cm}$ and severe low back pain measured by visual analogue scale of $>/=7$ requiring pain relief. Patient receiving opoid analgesics prior to inclusion in the study, patients with language barrier,

The papers in this journal are published under the terms of the Creative Commons Attribution License. Users are allowed to read, download, copy, distribute, print, search, or link to the full texts of the articles in this journal without asking prior permission from the publisher or the author. 
previous uterine scar, infection in area of injection were excluded from study. Informed consent as approved by the ethical committee of the institution was obtained from each participant.

The women were randomized into two groups according to computer generated random number table. The intervention group received simultaneously four subcutaneous injection of sterile water at four different sites in the lumbosacral region-Michaelis' rhomboid. The intervention group received four subcutaneous injection of sterile water in the lumbosacral region-Michaelis' rhomboid. The control group received four subcutaneous injection of isotonic saline in the same region. In both the groups, 1 $\mathrm{ml}$ insulin syringe with a fine needle (30 gauge) was used. Volume of each injection used was $0.1 \mathrm{ml}$. The injection of sterile water gave a sharp transient local pain sensation. In order to mask the difference in pain sensation between the two treatments, the injections were given during uterine contraction.

The pain score was measured prior to the injection and at 10, 45, 90 minutes after the injection using Visual Analogue Scale. The scale ranged from no pain ( 0 end) to unbearable pain (10 end). No rescue medication was used in the event of no pain relief following injection. Progress of labor was assessed according to labor room protocol. Mode of delivery and neonatal outcome were recorded. Data was analyzed using the SPSS (statistical program for the social sciences, SPSS Inc, Chicago, USA) software version 11.1. Student T test was used to compare continuous variables between intervention and control groups. For discrete variables Chi-square test was used for comparison. Level of significance was set at $5 \%(\mathrm{p}<0.05)$.

\section{RESULTS}

Two hundred and forty women were enrolled in the study and randomly divided equally into intervention and control groups. The two groups were not significantly different with regard to age, height, weight, parity, cervical dilatation and effacement (Table 1). All patients received the assigned treatment. None of the women delivered within 90 minutes after the injection and all completed the study.

The pain score prior to intervention was equal in both intervention and control groups. The mean pain score was reduced after injection in both groups, but the reduction was more pronounced in the intervention group $(\mathrm{p}<0.001)$ than in the placebo group at 10,45 , 90 minutes (Table 2 ).
Table 1. Baseline demographic and clinical data $(n=240)$.

\begin{tabular}{llll}
\hline Characteristics & $\begin{array}{l}\text { Intervention } \\
\text { group } \\
(\mathbf{n}=\mathbf{1 2 0})\end{array}$ & $\begin{array}{l}\text { Con trol } \\
\text { group } \\
(\mathbf{n = 1 2 0})\end{array}$ & $\begin{array}{l}\text { p- } \\
\text { value }\end{array}$ \\
\hline Mean age (years) & $23.6+3.8$ & $24.2+5.4$ & 0.354 \\
Mean height (cm) & $154+5.6$ & $154.3+5.8$ & 0.753 \\
Mean weight (kg) & $56.48+7.0$ & $57.19+7.8$ & 0.459 \\
$\begin{array}{l}\text { Cervical dilatation } \\
(\mathrm{cm})\end{array}$ & $4.58+0.77$ & $4.63+0.82$ & 0.630 \\
$\begin{array}{l}\text { Cervical } \\
\text { effacement (\%) }\end{array}$ & $70.42+5.8$ & $69.83+6.7$ & 0.475 \\
\hline
\end{tabular}

Out of 120 subjects in intervention group 104 subjects $(86.7 \%)$ had relief of low back pain, where as in the control group only 29 subjects $(24.2 \%)$ had reduction of low back labor pain. The difference was statistically significant. More than $94 \%$ of the women in each group had spontaneous vaginal deliveries. $5 \%$ in the intervention group had caesarean section where as $3.3 \%$ in control group had cesarean section. Similarly $0.8 \%$ in intervention group and $2.5 \%$ in control group had vacuum assisted vaginal delivery. The difference was statistically insignificant with $\mathrm{P}$ value being 0.497 . The mean Apgar scores of the babies in two groups were also comparable with no requirement for admission in neonatal unit.

Table 2. Comparison of pain scores between the intervention and control groups $(n=240)$.

\begin{tabular}{llrl}
\hline \multicolumn{1}{c}{ Intervention group } & Control group & $\begin{array}{l}\text { p- } \\
\text { value }\end{array}$ \\
\hline Pain score at 10 mins & $3.64+2.93$ & $7.63+2.16$ & $<0.001$ \\
Pain score at 45 mins & $3.27+2.68$ & $7.69+2.28$ & $<0.001$ \\
Pain score at 90 mins & $3.32+2.68$ & $4.63+0.82$ & $<0.001$ \\
\hline
\end{tabular}

Following delivery the women in both groups were assessed concerning the pain relief and were asked whether they want to use same treatment in subsequent delivery. Among 120 subjects in both intervention and control group 100 subjects $(83.3 \%)$ in intervention and 23 subjects (19.2\%) in control group wanted to use same technique in future pregnancy. The difference was statistically significant. On follow up there were no complaints of residual pain at the injection site.

\section{DISCUSSION}

The analgesic property of sterile water had been recognized long back. It was first mentioned in the literature by Halsted in $1885 .^{3}$ The analgesic property of sterile water can be explained by gate control theory which was introduced by Melzack et al. ${ }^{2}$ Injection of sterile water stimulates nociceptors 
and may lead to condition called counter-irritation or hyperstimulation which may also explain the analgesic property of sterile water. Counterir-ritation is a phenomenon in which one painful stimuli reduces pain caused by second noxious stimuli. ${ }^{4}$ Sterile water injections has also been used for treatment of pain other than labor pain including pain of urolithiasis, neck and shoulder pain with positive results. ${ }^{5-7}$ The study was conducted with the total sample size of 240 of which 120 were intervention and remaining the control group, which was larger sample size than most of the previous studies. ${ }^{4,8}$

Intracutaneous injections of sterile water have also been shown to be effective in reducing pain in labor as observed in the study done by Wiruchpongsanon. ${ }^{8}$ Despite good relief of pain, women were reluctant to receive the same treatment for another delivery as observed in the study by Labrecque et al. ${ }^{9}$ They attributed it to the short lasting intense pain that accompanies intracutaneous sterile water injections. Further, subcutaneous injections of sterile water are shown to be less painful and more tolerable than intracutaneous injections as shown in the study by Martensson et al. ${ }^{10}$ Since the two methods are comparable in terms of cost, access and pain relief, subcutaneous method of administration of sterile water was chosen in our study. The placebo group was given injections of isotonic (normal) saline solution. Although subcutaneous normal saline has also been shown to produce some analgesia through placebo effect, it is not up to the level of clinical significance and therefore we chose it as control in our study.

The limitation of this study is that pain score was assessed at three specific times after the injection so the evaluation of pain relief was restricted to 90 minutes only and maximum duration of pain relief was not assessed, moreover we did not use any rescue medications for low back pain if there was any. This study clearly demonstrated an effective analgesia with subcutaneous sterile water injection of sterile water for low back labor pain during the first stage of labor and added further evidence to the finding by previous investigators.

Though epidural analgesia is the most effective method for relieving labor pain, it is not available in many centers due to paucity of anesthesiologists, and not every patient can afford the service. Narcotics can also reduce the pain of labor but this method is limited because of its side effects like maternal drowsiness, neonatal respiratory depression, nausea and vomiting. Therefore, sterile water injection seems to be a feasible, efficient, simple and cheap alternative for relief of low back pain during labor.

\section{CONCLUSIONS}

Administering subcutaneous sterile water injection at painful point of lumbosacral area was effective in reducing low back pain during labor. The rate of operative delivery and neonatal outcome were not different from the control group. The women whose pain was relieved were extremely satisfied with the procedure. Eighty three percent of the subjects receiving sterile water wanted to use it in future pregnancy for pain relief. Therefore, subcutaneous water can be taken as a feasible analgesic alternative in laboring women with severe continuous low back pain.

\section{REFERENCES}

1. Melzack R, Schaffelberg D. Low-back pain during labor. Am J Obstet Gynecol. 1987;156(4):901-5.

2. Melzack R, Wall PD. Pain mechanism: a new theory. Science. 1965;150(3699):971-9.

3. Halsted W. Water as a local anaesthetic. Med J. 1885;3:237.

4. Bahasadri S, Ahmadi-Abhari S, Dehghani-Nik M, Habibi GR. Subcutaneous sterile water injection for labour pain: a randomized controlled trial. Aust N Z J Obstet Gynaecol. 2006;46(2):102-6.

5. Bengtsson J, Worning AM, Gertz J, Struckmann J, Bonnesen T, Palludan $\mathrm{H}$, et al. Pain due to urolithiasis treated by intracutaneous injections of sterile water: a clinically controlled double-blind study. Ugeskr Laeger. 1981;143(51):3463-5.

6. Byrn C, Borenstein P, Linder LE. Treatment of neck and shoulder pain in whiplash syndrome patients with intracutaneous sterile water injections. Acta Anaesthesiol Scand. 1991;35(1):52-3.

7. Byrn C, Olsson I, Falkheden L, Lindh M, Hosterey U, Fogelberg M, et al. Subcutaneous sterile water injections for chronic neck and shoulder pain following whiplash injuries. Lancet. 1993;341(8843):449-52.

8. Wiruchpongsanon P. Relief of low back labor pain by using intracutaneous injections of sterile water: a randomized clinical trial. J Med Assoc Thai. 2006;89(5):571-6.

9. Labrecque $M$, Nouwen A, Bergeron $M$, Rancourt JF. A randomized controlled trial of non-pharmacologic approaches for pain relief of low back pain during labor. J Fam Pract. 1999;48(4):259-63.

10. Martensson L, Nyberg K, Wallin G. Subcutaneous versus intracutaneous injections of sterile water for labor analgesia: a comparison of perceived pain during administration. Brit J Obstet Gynecol. 2000;107(10):1248-51. 